\title{
Avaliação Remota de Usabilidade do Site do Campus Alegrete da Unipampa
}

\author{
Ícaro Machado Crespo, Marina Braun Otokovieski, Amanda Meincke Melo \\ ${ }^{1}$ Universidade Federal do Pampa (Unipampa) - Campus Alegrete \\ Av. Tiarajú, 810 - 97.546-550 - Alegrete - RS - Brazil \\ \{icarocrespo, marinaotok\}@gmail.com, amandamelo@unipampa.edu.br
}

\begin{abstract}
This article presents the Unipampa Campus Alegrete Usability Assessment process and its results. The evaluation took place in two stages, supported by the USE Questionnaire, SAM Instrument and Online Cooperative Assessment, these methods were adapted for remote work, with Campus students as a target audience. In each of its stages, it had different numbers of users, 47 and 6, respectively. As results, we present the interpretation of the data obtained related to the perception of usability by users, as well as the execution of tasks by some of these users and their emotions when performing them. At the end, it can be seen that improvements must be made to enrich the user experience.
\end{abstract}

Resumo. Este artigo apresenta o processo de Avaliação de Usabilidade do site do Campus Alegrete da Unipampa e seus resultados. A avaliação ocorreu em duas etapas, apoiadas pelo Questionário USE, instrumento SAM e Avaliação Cooperativa Online, métodos estes adaptados para o trabalho remoto, tendo como público-alvo os estudantes do Campus. Cada uma das etapas, contou com quantitativos de usuários distintos, sendo 47 e 6, respectivamente. Como resultados, apresentam-se a interpretação para os dados obtidos sobre a percepção da usabilidade pelos usuários, assim como da execução de tarefas por alguns desses usuários e de suas emoções ao realizá-las. Ao final, pode-se observar que melhorias devem ser realizadas para aprimorar a experiência do usuário.

\section{Introdução}

Com a adoção crescente de tecnologias de informação e comunicação (TIC) e a facilidade de uso da Internet, sistemas web são saídas comuns para acesso à informação tanto no meio privado quanto no meio público [Pereira et al. 2012]. A partir da implantação de leis que abordam temas relacionados a essas tecnologias, especialmente a Lei de Acesso à Informação [Brasil 2011], a qual dispõe no inciso I do artigo $7^{\circ}$ que, entre outros, há o direito de se obter: "orientação sobre os procedimentos para a consecução de acesso, bem como sobre o local onde poderá ser encontrada ou obtida a informação almejada.", faz-se necessário avaliar sistemas eletrônicos a fim de analisar o seu cumprimento.

A Interação Humano-computador (IHC), comumente integrada à Engenharia de Software (ES), é uma área que se preocupa com o desenvolvimento, a avaliação e os fenômenos envolvidos na adoção de sistemas computacionais interativos para uso humano [Hewett et al. 1992]. A ISO 9241-11 dispõe sobre a Usabilidade como sendo "O grau em que um produto é usado por usuários específicos para atingir objetivos específicos com eficácia, eficiência e satisfação em um contexto específico de uso." [Barbosa and Silva 2010]. 
Nesse sentido, avaliar interfaces de usuário para a garantia da qualidade da experiência do usuário é uma das atividades necessárias para manutenção de um sistema computacional interativo no cumprimento de seus objetivos e legislação vigente. Tendo em vista algumas dificuldades percebidas pela gestão da Unidade Acadêmica sobre o site do Campus Alegrete ${ }^{1}$, uma solicitação ao GEIHC - Grupo de Estudos em Interação Humano-computador foi feita para realizar uma avaliação de usabilidade sobre esse domínio. Tais informações estão consolidadas em um relatório para envio à parte competente da Instituição, a Diretoria de Tecnologia da Informação e Comunicação (DTIC), para sua apreciação e possível resolução dos problemas levantados.

São objetivos dessa avaliação: 1. mensurar a usabilidade do site do Campus Alegrete; 2. sumarizar os problemas, pontos fortes e fracos do sistema. Tendo em vista o período de exceção causado pela pandemia de COVID-19, um conjunto de técnicas e métodos adaptados para o contexto remoto foi utilizado na condução do estudo [Melo et al. 2020].

\section{Metodologia}

Este trabalho é baseado em uma abordagem quantitativa e qualitativa de pesquisa, de caráter exploratório [Triviños 1987], envolvendo a observação e a interpretação das experiências de avaliação de interface de usuário no contexto do projeto de ensino GEIHC. O público-alvo deste estudo foi constituído por estudantes pertencentes aos sete cursos de graduação do Campus Alegrete, os quais colaboraram em duas etapas com abordagens distintas descritas a seguir. Os convites de ambas as etapas foram enviados aos e-mails institucionais dos estudantes de graduação do Campus. Para a Etapa 2, o convite foi enviado àqueles que demostraram interesse em continuar contribuindo ao estudo.

\subsection{Etapa 1}

A Etapa 1 consistiu na aplicação de uma versão adaptada do questionário USE (do inglês Usefulness, Satisfaction and Ease of Use) [Lund 2001], que significa Utilidade, Satisfação e Facilidade de Uso e se propõe a mensurar a usabilidade de um produto. O questionário foi elaborado na plataforma Google Forms e ficou disponível para coleta de respostas durante uma semana (de 10/06/2020 a 17/06/2020).

O questionário foi dividido em duas seções: uma contendo as informações pessoais e outra contendo as questões do USE. Foram solicitadas informações pessoais, sugestões de melhoria e uma pergunta sobre o interesse em colaborar na próxima etapa da avaliação. Destaca-se que a matrícula foi solicitada a fim de saber o ano de ingresso, uma vez que ela é um indicativo dessa informação sobre o estudante. No que diz respeito às questões do USE, estas foram categorizadas em quatro eixos, de acordo com [Lund 2001]: 1. Utilidade; 2. Facilidade de uso; 3. Facilidade de aprendizado; 4. Satisfação. Para cada uma das 30 questões próprias do USE, foi adotada uma escala Likert de 7 pontos (1 a 7) [Albaum 1997], onde seus extremos descrevem "Discordo plenamente" e "Concordo plenamente", como mostra o extrato do instrumento na Figura 1 .

\footnotetext{
${ }^{1}$ https://www.unipampa.edu.br/alegrete

${ }^{2}$ Questionário USE disponível em: https://bit.ly/questionarioUSE
} 


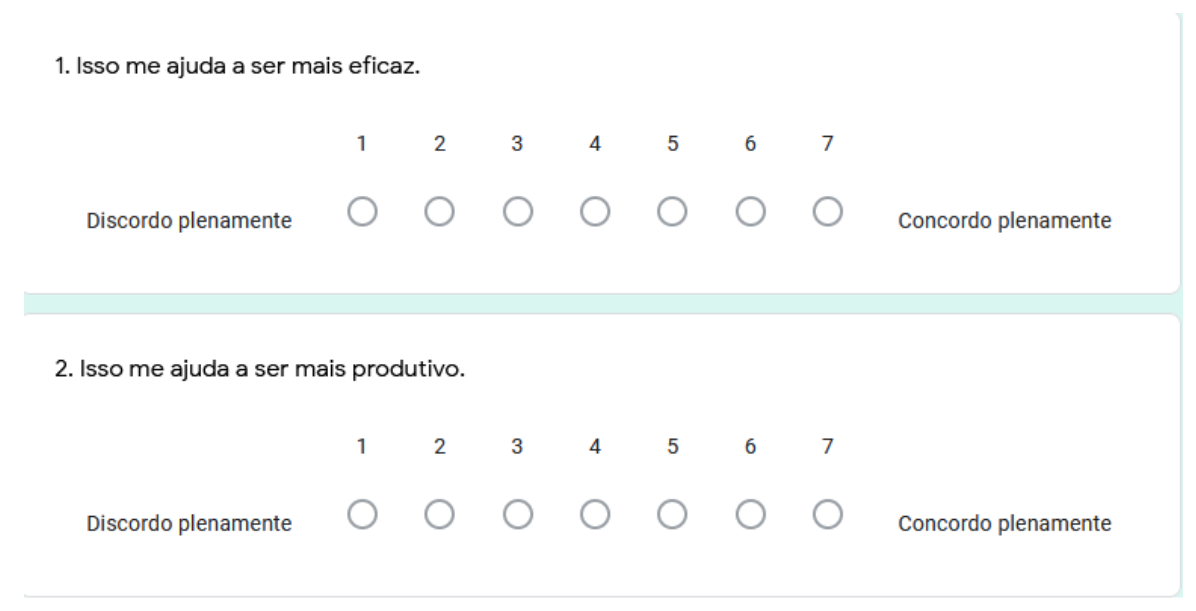

Figura 1. Extrato do questionário USE

\subsection{Etapa 2}

A Etapa 2 contou com dois processos, a Avaliação Cooperativa Online e a aplicação do instrumento SAM (do inglês, Self Assessment Manikin) ao final de cada tarefa. Para a execução de maneira totalmente remota do estudo, foi utilizada uma adaptação dessas técnicas, como descrito em [Melo et al. 2020], ao invés de seu emprego de maneira física. A etapa ocorreu entre os dias 23 e 27/07/2020, contando com a participação efetiva de seis usuários que demonstraram interesse em continuar a avaliação. Com o consentimento dos participantes, as sessões foram gravadas para análise posterior de fluxos e ações.

A Avaliação Cooperativa Online propõe a avaliação de interfaces de usuário, envolvendo a cooperação entre desenvolvedor e usuário, explorando um protótipo ou sistema de software, desenvolvendo uma crítica [Muller et al. 1997]. Ao adaptar o uso da técnica [Melo and Baranauskas 2006], propõe-se a realização de tarefas pelo usuário e sua observação pelo desenvolvedor ou responsável pela sessão de avaliação.

O instrumento SAM é constituído por imagens, criado para avaliar o estado afetivo de pessoas em relação a eventos ou estímulos. Essa avaliação ocorre em três dimensões, as quais possuem uma série de imagens ordenadas de acordo com o seu grau. A dimensão Prazer varia de uma figura feliz a uma figura infeliz; a dimensão Excitação varia de uma figura animada a uma figura sonolenta; e a dimensão Dominância varia de uma figura pequena, caracterizando a falta de domínio da situação, a uma figura grande que indica o contrário [Bradley and Lang 1994].

Os membros do grupo desenvolveram cinco tarefas apresentadas na Tabela 1 para a condução da segunda etapa do estudo. As tarefas foram elaboradas com base na percepção do grupo de avaliadores, após consenso, sendo algumas consideradas mais complexas do que outras em termos de usabilidade e familiaridade com o domínio. O instrumento SAM foi aplicado via formulário disponibilizado na web, conforme ilustra a Figura 2, e foi aplicado ao final da execução de cada tarefa em suas três dimensões.

\section{Resultados e Discussão}

Nesta seção são apresentados e discutidos os dados coletados durante o estudo. Houve significativa contribuição nos questionamentos dissertativos, sendo que dos 47 participantes na Etapa 1, 33 mencionaram interesse em continuar colaborando com a avaliação do 
Tabela 1. Tarefas observadas durante a Avaliação Cooperativa Online

\begin{tabular}{|c|l|}
\hline Tarefa & Descrição \\
\hline 1 & Acessar o Plano de Permanência \\
\hline 2 & Acessar a ata número 11 do Conselho do Campus Alegrete, de 2019 \\
\hline 3 & Identificar os horários de aulas do segundo semestre de 2019 \\
\hline 4 & Acessar formulário de solicitação de dispensa para afastamento \\
\hline 5 & Informar a carga horária do Curso de Engenharia Mecânica \\
\hline
\end{tabular}

Tarefa 1 *

Prazer
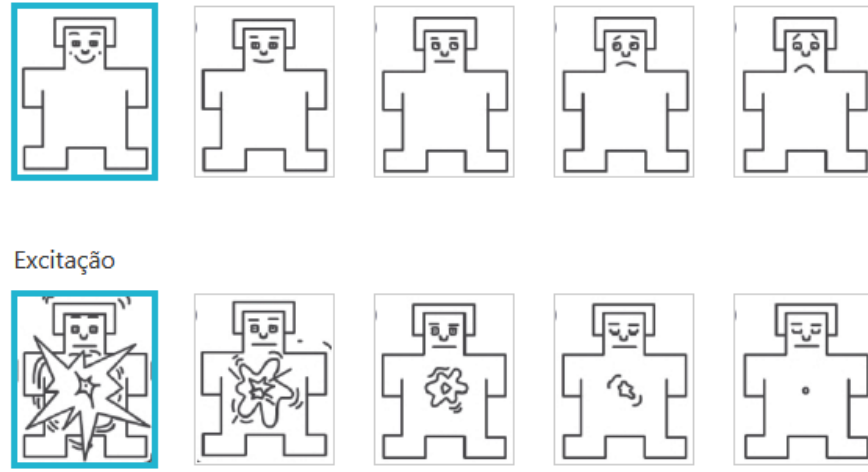

Dominância

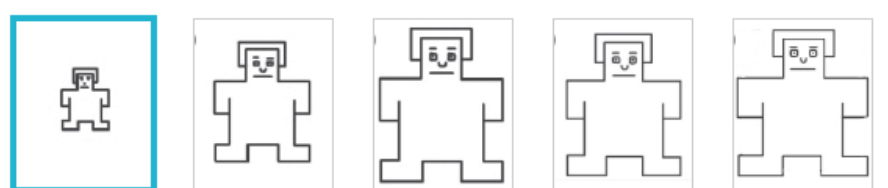

Figura 2. Extrato do instrumento SAM

site e 14 foram convidados a colaborarem na Etapa 2. O critério de seleção desses participantes foi a heterogeneidade de cursos e a carga de trabalho para os pesquisadores. Dos 14 convidados à Etapa 2, seis compareceram aos encontros marcados.

\subsection{Etapa 1}

Sobre o perfil dos respondentes, houve aderência maior daqueles estudantes com faixa etária entre 20 e 24 anos, como mostra a Figura 3 . Em segundo lugar, estão os respondentes com faixa etária abaixo de 20 anos. Isso pode estar relacionado a muitos estudantes entrarem no ensino superior logo após o término do ensino básico. As faixas etárias de 30 a 34 anos e 35 a 39 anos totalizaram 1 e 2 participantes, respectivamente.

Para a análise das respostas às questões do USE, organizadas em seus quatro eixos, foram consideradas as classificações entre 1 e 3 como "rejeição", 4 como "aceitação neutra" e entre 5 e 7 como "boa aceitação". Utilizou-se para a elaboração dos gráficos o modelo de empilhamento, onde tons de verde representam uma aceitação maior às cores amarela, laranja e vermelha.

No primeiro eixo do questionário USE (Utilidade) (Figura 4), para todas as questões, mais da metade dos usuários reportaram uma "boa aceitação" enquanto que 


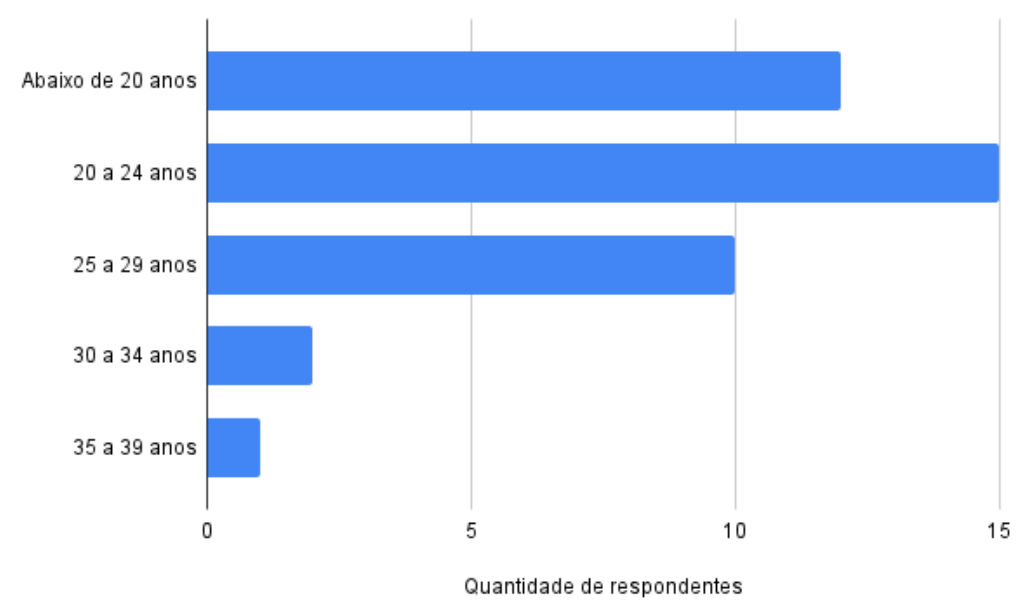

Figura 3. Etapa 1: Faixa etária dos respondentes

menos de 25\% indicaram "rejeição". Nesse eixo, apenas a questão Q3 "É útil" não apresentou qualquer tipo de "rejeição", com uma "boa aceitação" superior à $75 \%$.

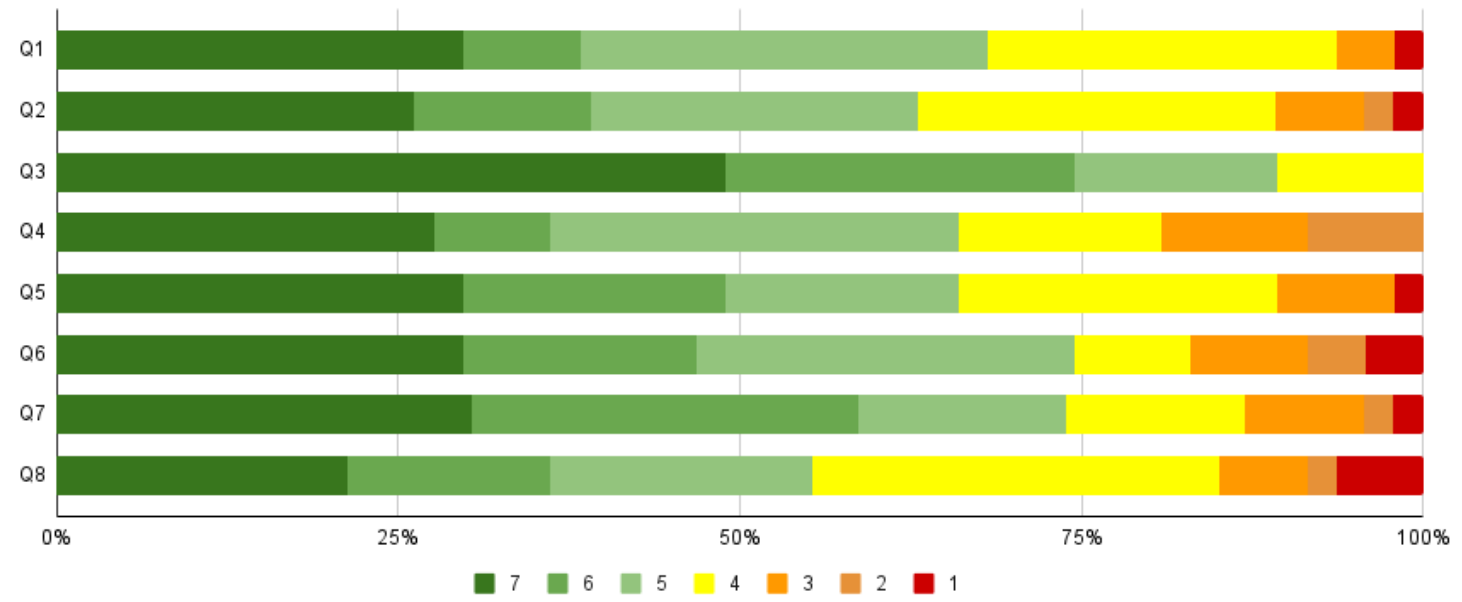

Figura 4. Eixo Utilidade do questionário USE

Do mesmo modo, no segundo eixo (Facilidade de uso) (Figura 5), em todas as questões, mais da metade dos usuários relataram uma "boa aceitação". Contudo, a questão Q12 "Requer o menor número possível de etapas para realizar o que quero fazer com isso" apresentou "rejeição" superior a 25\%. Para as demais questões, menos de $25 \%$ dos respondentes indicaram algum tipo de rejeição.

Já no terceiro eixo (Facilidade de aprendizado) (Figura 6), para todas as questões, mais de 75\% dos usuários atribuíram uma "boa aceitação", destacando-se quanto à rejeição a questão Q23 "Eu rapidamente me tornei hábil nisso".

Por fim, no último eixo (Satisfação) (Figura 7), os dados apresentam maior variação na percepção dos respondentes. Nesse eixo, ambas as questões Q26 "É divertido de usar" e Q27 "Funciona da maneira que eu quero que funcione" apresentam "boa aceitação" entre $25 \%$ e $50 \%$. Essas mesmas questões apresentam "rejeição" superior à 


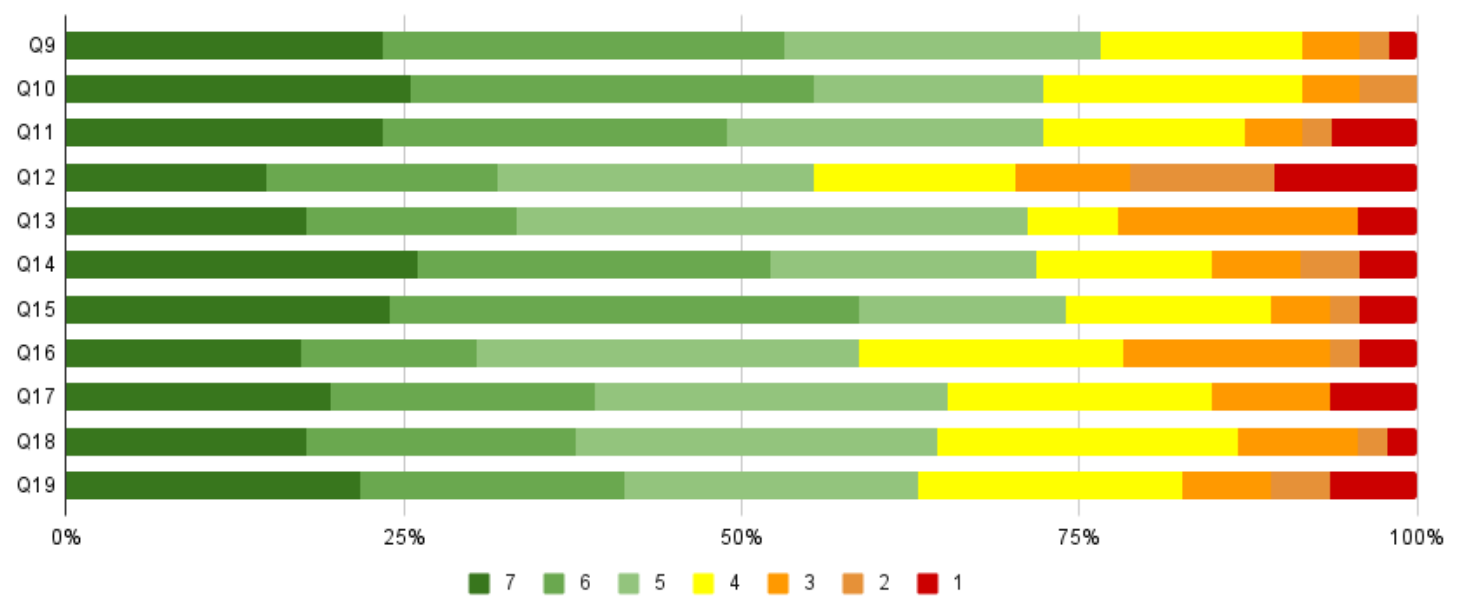

Figura 5. Eixo Facilidade de uso do questionário USE

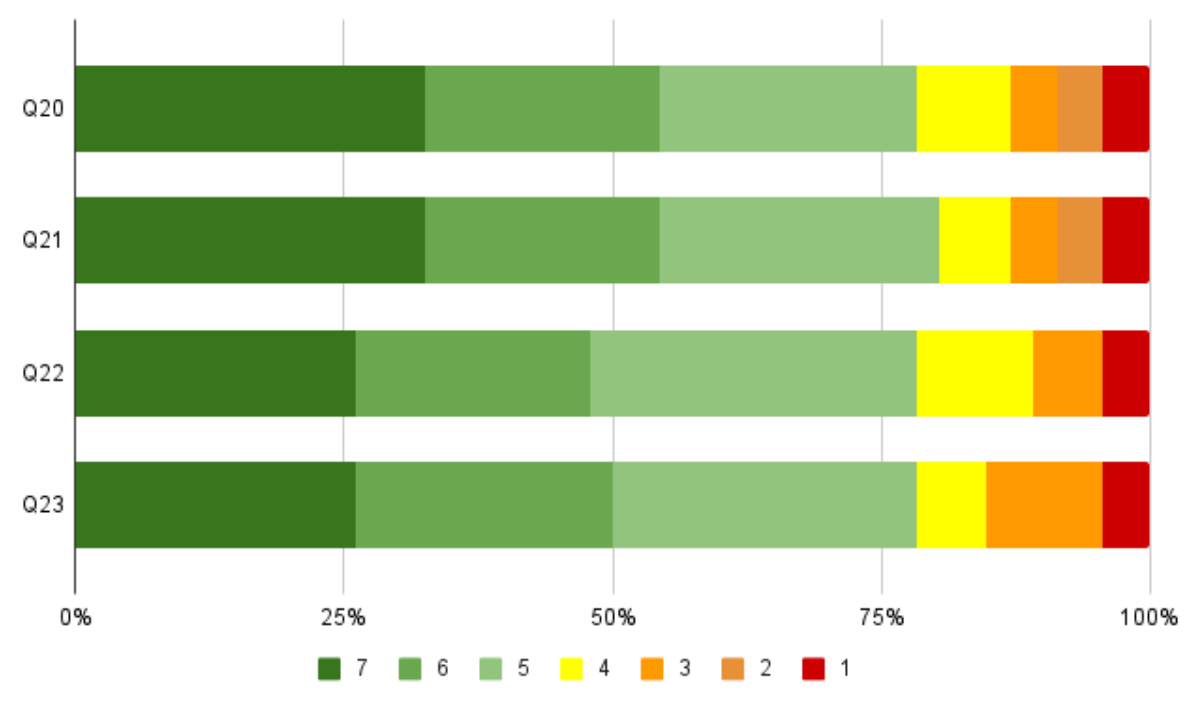

Figura 6. Eixo Facilidade de aprendizado do questionário USE

25\% juntamente com a Q28 "É maravilhoso".

Quanto à esta etapa de avaliação, pôde-se perceber que o eixo mais bem avaliado foi a Facilidade de aprendizado, sendo que a questão Q21 "Lembro-me facilmente de como usá-lo"é a que apresenta o maior número de respostas que indicam "boa aceitação"para os usuários que avaliaram o site. Já o eixo com pior avaliação foi o da Satisfação, destacando-se quanto à "rejeição"a questão Q28 "É maravilhoso", mas também as questões Q26 "É divertido de usar"e Q27 "Funciona da maneira que eu quero que funcione". Além disso, é importante reiterar, no eixo Facilidade de uso, que o quesito Q12 "Requer o menor número possível de etapas para realizar o que quero fazer com isso"também apresentou maior "rejeição".

Observa-se, ainda, que segundo os usuários, entre os aspectos positivos, estão a organização das atividades na palma da mão de forma fácil e melhor produtividade em relação às atividades acadêmicas. Já entre os aspectos negativos, muitos apontaram que 


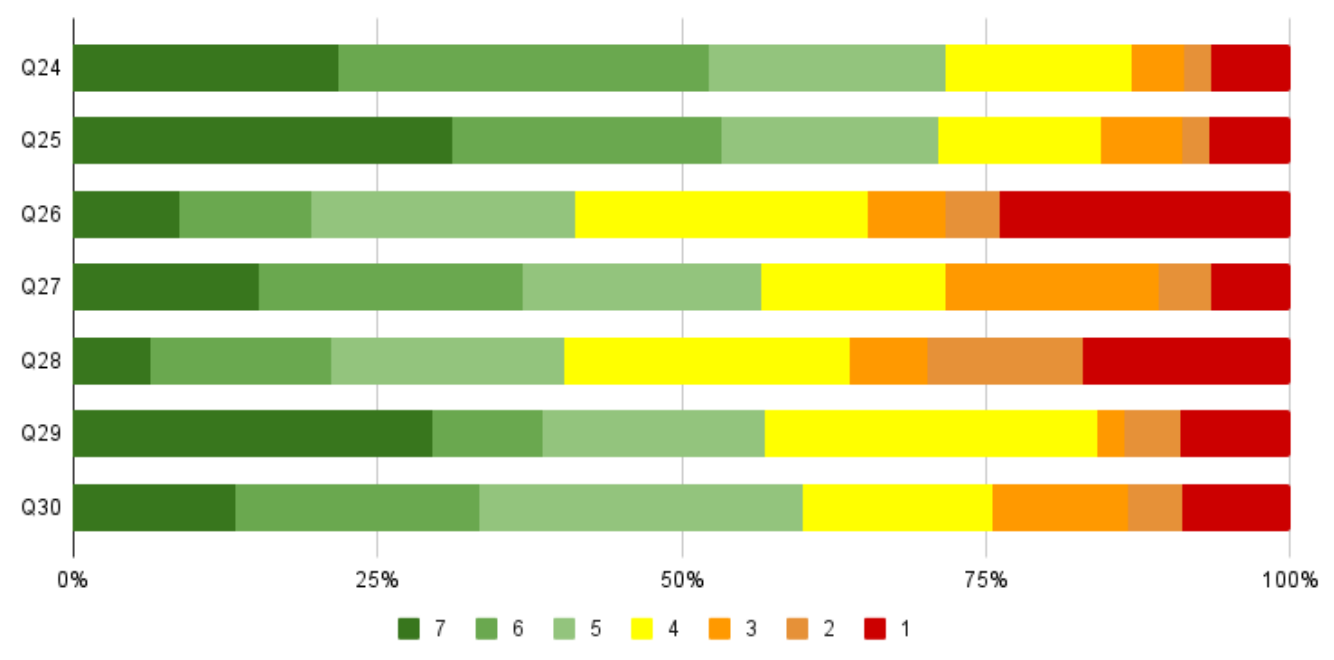

Figura 7. Eixo Satisfação do questionário USE

não puderam identificar informações desejada e apenas um estudante revelou estar com dúvidas sobre como algumas funcionalidades se comportariam. A Tabela 2 apresenta, de acordo com as respostas às questões abertas do questionário USE, um conjunto de problemas informados pelos participantes da etapa.

Tabela 2. Problemas apontados no questionário USE

\begin{tabular}{|l|c|}
\hline Problema & Número de repetições \\
\hline Navegação complexa e não intuitiva & 6 \\
\hline Informações dispostas de maneira não usual & 5 \\
\hline Sobrecarga no fluxo do sistema & 5 \\
\hline Indisponibilidade do sistema & 4 \\
\hline Informações inconsistentes ou desatualizadas & 2 \\
\hline Dificuldade para encontrar arquivos para visualização & 1 \\
\hline Não padronização em fontes de texto & 1 \\
\hline
\end{tabular}

\subsection{Etapa 2}

Como resultado da condução das cinco tarefas (Tabela 1), aponta-se que nem todas foram realizadas pelos participantes, como ilustra a Figura 8, a qual também indica a performance dos participantes na execução das tarefas. Junto a isso, a Tabela 3 apresenta os comentários pontuais feitos pelos observadores no momento da condução das tarefas. Sobre o instrumento SAM, nesta seção são apresentados apenas dois gráficos em virtude de sua relevância e disponibilidade de espaço neste artigo.

Em relação à tarefa 2 "Acessar a ata número 11 do Conselho do Campus Alegrete, de 2019.", não foi realizada por dois participantes, pois divergiam de seus modelos mentais. Esse ponto pode estar atrelado ao fato de não conseguirem localizar as atas do órgão e, mais especificamente, pela página apresentar mais de um número 11 (id e em relação à $11^{\text {a }}$ reunião do órgão). Ainda, apenas o participante 2 indicou os valores máximos nos eixos prazer e excitação do instrumento SAM. Para essa tarefa, o eixo dominância variou de acordo com os participantes, onde o participante 4, ao mesmo tempo que não conse- 
guiu cumpri-la nos 4min da tarefa, atribuiu o valor mínimo (1) em relação aos três eixos. Isso pode estar atrelado ao nível de insatisfação ao não conseguir efetuar a tarefa.

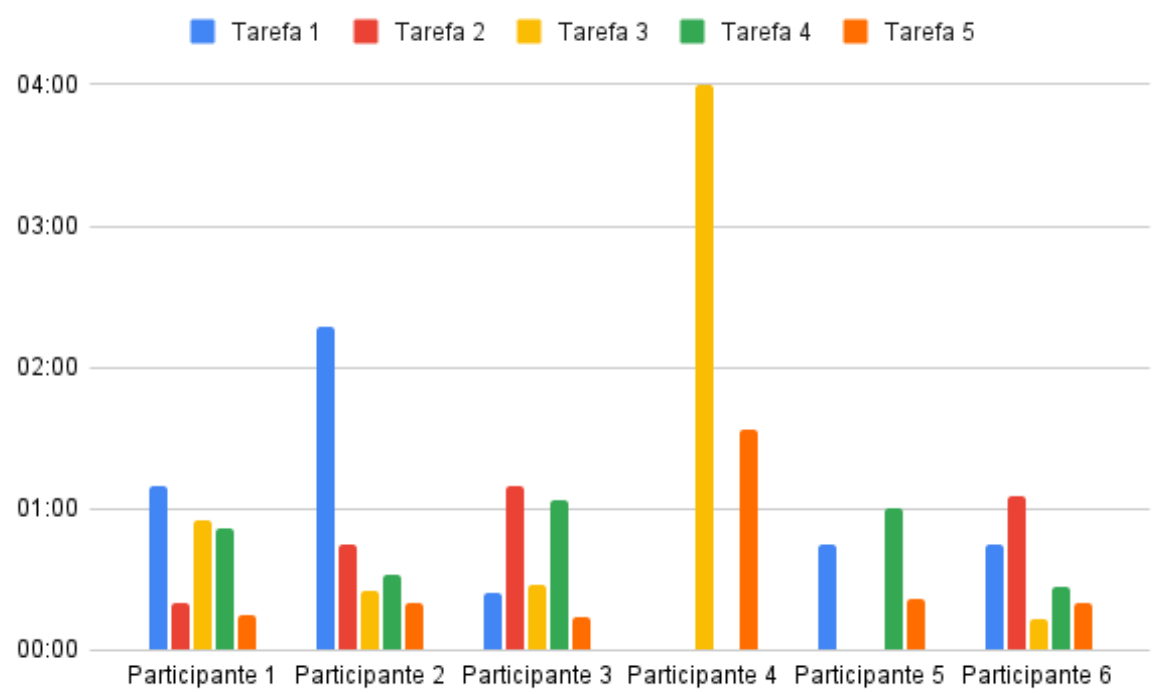

Figura 8. Etapa 2: Performance dos respondentes

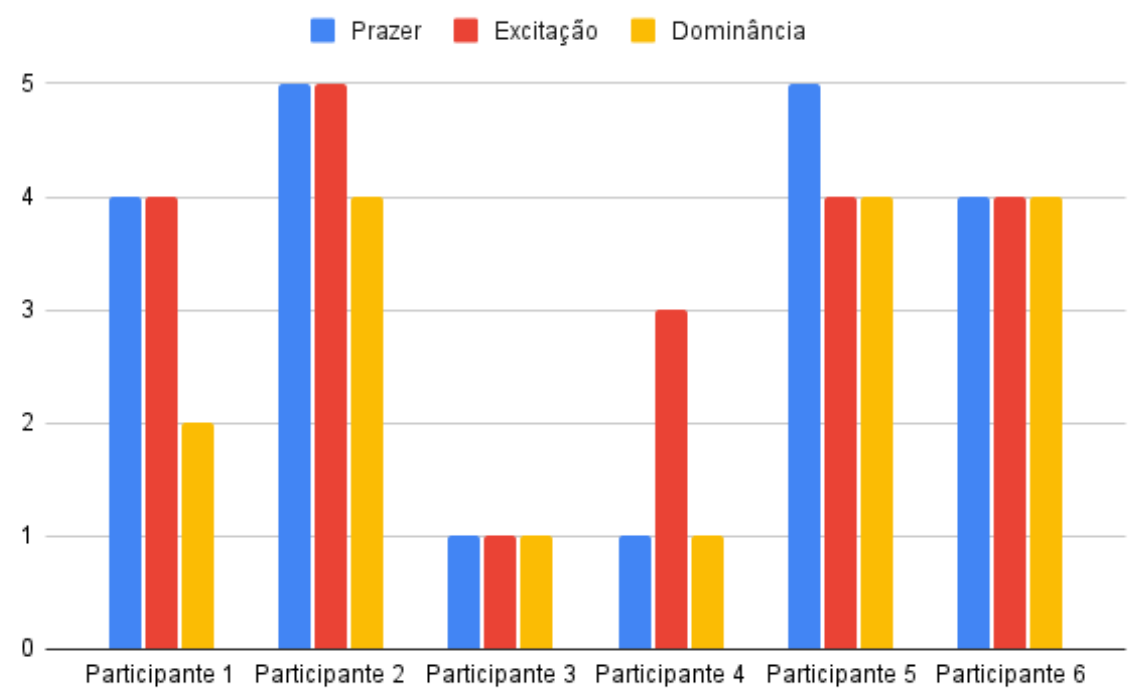

Figura 9. Etapa 2: instrumento SAM - Tarefa 2

Sobre a tarefa 3 "Identificar os horários de aulas do segundo semestre de 2019", aponta-se que o participante 4 chegou ao tempo-limite para a sua execução. Esse mesmo participante concluiu apenas a outra tarefa de número 5 "Informar a carga horária do Curso de Engenharia Mecânica", sendo ainda o tempo para a conclusão desta superior a 1,5min. Um dos fatores que pode ser levado em consideração na realização deste estudo é o fato de esse participante ser ingressante, podendo ter acessado poucas vezes o site, mostrando falta de dominância nele.

Já a tarefa 4 "Acessar formulário de solicitação de dispensa para afastamento" foi concluída por todos os participantes em um tempo menor do que 1,5min. Essa tarefa 


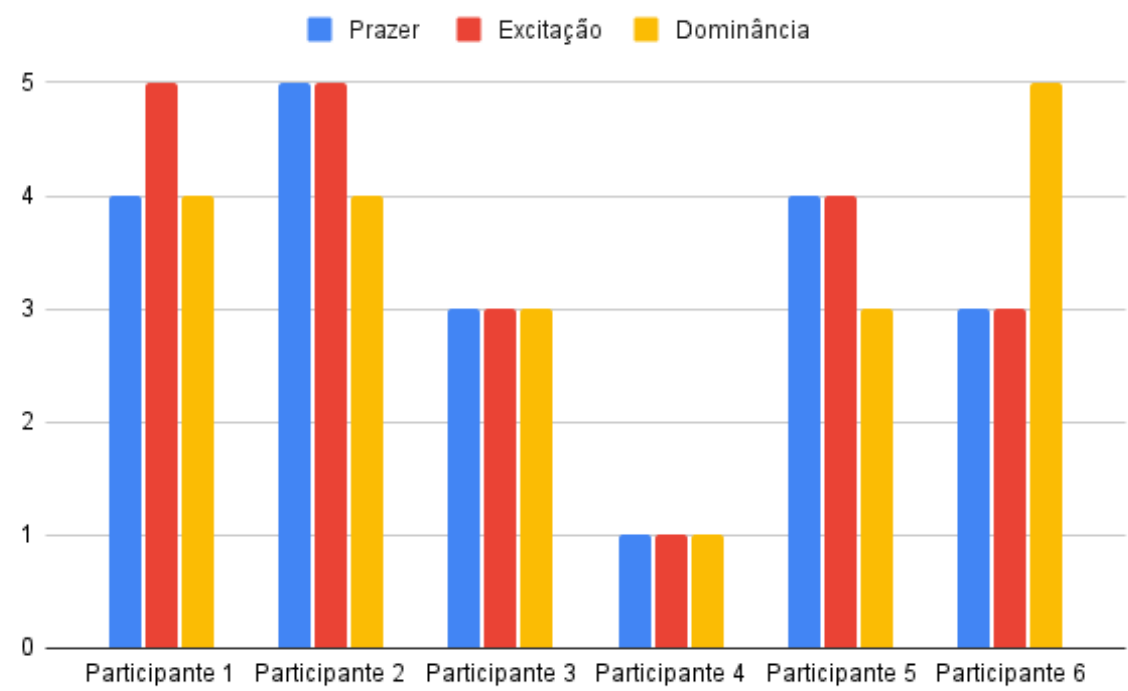

Figura 10. Etapa 2: instrumento SAM - Tarefa 4

para os estudantes é frequentemente realizada, de acordo com perguntas realizadas pelos observadores ao final da Avaliação Cooperativa Online. Em contrapartida, ao tentarem localizar a informação, foi apontado por todos que a disposição da página não favorece a sua utilização. De acordo com os participantes, sobrecarregada, fazendo alusão ao problema elencado na Tabela 2 '"Informações dispostas de maneira não usual".

Tabela 3. Comentários da Etapa 2

\begin{tabular}{|c|c|}
\hline Part. & Comentário \\
\hline 1 & Tentou buscar sempre pela caixa de pesquisar, mas não encontrou uma resposta. \\
\hline 2 & $\begin{array}{l}\text { Usuário saiu do escopo do Campus Alegrete para achar a informação, usou o Google para } \\
\text { buscar. }\end{array}$ \\
\hline 3 & Usuário em alguns momentos utilizou o rodapé para procurar informações. \\
\hline 4 & $\begin{array}{l}\text { Tentou utilizar a caixa de busca. Usuário saiu do escopo do Campus Alegrete. A busca é } \\
\text { fraca, não cumpre a tarefa de busca. }\end{array}$ \\
\hline 5 & $\begin{array}{l}\text { O usuário desenvolveu as atividades com mais facilidades aquelas que ele já havia executado } \\
\text { anteriormente. As demais tiveram uma dificuldade similar a de ingressantes. }\end{array}$ \\
\hline 6 & $\begin{array}{l}\text { A caixa de pesquisa retornou o que requisitou. Clicou no link do Curso de Engenharia } \\
\text { Mecânica como outros. }\end{array}$ \\
\hline
\end{tabular}

Destaca-se que os usuários buscaram fora do domínio as informações necessárias, pois a busca oferecida pelo site não contemplou suas necessidades, como registrado na Tabela 3. Além disso, diversas vezes os usuários utilizaram o organograma do rodapé para executarem as tarefas, mas sem êxito. Ficou perceptível que o participante que já havia executado a tarefa elencada (participante 5) não possuiu dificuldade para realizá-la. Porém, ao realizar uma tarefa fora de seu domínio, apresentou dificuldades semelhantes a de ingressantes na Instituição.

\section{Considerações Finais}

Em relação ao cumprimento de aspectos legais sobre o acesso à informação, percebe-se haver dificuldades no que diz respeito a localizar as informações almejadas. Segundo 
os participantes deste estudo, a navegação é complexa e não intuitiva. Ademais, as informações estão dispostas de maneira não usual. Na Avaliação Cooperativa Online esse aspecto é reiterado: além de os usuários precisarem recorrer a mecanismo de busca externo, apresentaram dificuldades para encontrar as informações nas próprias páginas. Isso se reflete diretamente na Satisfação de uso do site.

Além do aumento de credibilidade ao site, a correção dos problemas elencados é um importante passo para o aperfeiçoamento da experiência dos usuários desse site. Aponta-se que essas atividades de avaliação devem ser realizadas rotineiramente, a fim de levantar dados sobre as percepções dos usuários sobre o domínio. Com base nas sugestões e críticas, é possível fornecer insumos para tomadas de decisão pelos órgãos competentes e implementação pontual das inconsistências elicitadas para sua evolução.

\section{Referências}

Albaum, G. (1997). The likert scale revisited. Market Research Society. Journal, 39(2):121.

Barbosa, S. and Silva, B. (2010). Interação humano-computador. Elsevier Brasil.

Bradley, M. M. and Lang, P. J. (1994). Measuring emotion: the self-assessment manikin and the semantic differential. Journal of behavior therapy and experimental psychiatry, 25(1):49-59.

Brasil, C. N. (2011). Lei $\mathrm{n}^{\circ}$ 12.527, de 18 de novembro de 2011. Disponível em: http://www.planalto.gov.br/ccivil_03/_ato2011-2014/2011/lei/112527.htm. Acessado em 18 de out. de 2021.

Hewett, T. T., Baecker, R., Card, S., Carey, T., Gasen, J., Mantei, M., Perlman, G., Strong, G., and Verplank, W. (1992). ACM SIGCHI curricula for human-computer interaction. ACM.

Lund, A. M. (2001). Measuring usability with the use questionnaire12. Usability interface, $8(2): 3-6$.

Melo, A. M. and Baranauskas, M. C. C. (2006). Uma opção inclusiva à avaliação cooperativa de interfaces de usuário. SEMINÁRIO INTEGRADO DE SOFTWARE E HARDWARE, 23:447-461.

Melo, A. M., Crespo, Í. M., Medeiros, G. C., and de Oliveira, A. B. (2020). Estratégias remotas à avaliação de interfaces de usuário. In Anais da IV Escola Regional de Engenharia de Software, pages 245-254. SBC.

Muller, M. J., Haslwanter, J. H., and Dayton, T. (1997). Participatory practices in the software lifecycle. In Handbook of human-computer interaction, pages 255-297. Elsevier.

Pereira, G. V., Macadar, M. A., and Becker, G. V. (2012). Análise do uso do portal de periódicos da capes em uma ies sob perspectiva institucional. Análise-Revista de Administração da PUCRS, 23(1):78-90.

Triviños, A. (1987). Introdução à pesquisa em ciências sociais: a pesquisa qualitativa em educação. Atlas. 